\title{
ESPECIAL
}

\section{Qual é o futuro do trabalho na Era Digital?}

\author{
What is the future of work in the digital age?
}

\section{Ricardo Antunes ${ }^{1}$}

Poucos temas são tão controversos como o trabalho. Fora de moda nas décadas de 1980/90, tornou-se novamente temática crucial do nosso tempo. Terceirização, informalidade, flexibilidade, trabalho intermitente, subemprego, desemprego, nenhuma dessas palavras podem ser compreendidas e decifradas sem uma análise conectada com o mundo do trabalho e da produção de nosso tempo.

Foi a partir da crise estrutural, que aflorou no início de 1970 (MÉSZÁROS, 2002; CHESNAIS, 1996) - e que se intensificou a partir de 2008 - que os capitais desencadearam um vasto processo de reestruturação produtiva que resultou em formas de acumulação flexível, caracterizada pela deslocalização produtiva, pela expansão das redes de subcontratação, pelo trabalho em equipe, salários flexíveis, "células de produção", "times de trabalho", "envolvimento participativo", "trabalho polivalente", "multifuncional', com o objetivo primeiro de reduzir os custos e aumentar a produtividade (ANTUNES, 2014; 2018).

A pragmática das "metas" e das "competências", diuturnamente efetivada pelo admirável mundo dos "colaboradores", tudo isso se converteu no novo ideário do mundo produtivo, no que já apresentei como sendo o novo elixir da vida empresarial. Ao expandir-se para os mais diversos ramos industriais, agrícolas e de serviços, a terceirização, que no passado recente era a exceção, vem se convertendo em regra.

O resultado está em toda parte: precarização ampliada e multiforme, onde os trabalhadores e trabalhadoras são as vítimas principais. Em épocas de expansão, ampliam-se os empregos, como no setor de serviços, dotados de alta rotatividade, pouca qualificação e baixa remuneração, de que são exemplos os trabalhos nas

1 Professor titular de Sociologia no Instituto de Filosofia e Ciências Humanas da Universidade Estadual de Campinas, São Paulo, Brasil. - rlcantunes53@gmail.com 
plataformas digitais e nos aplicativos, no telemarketing e call center, hipermercados, hotéis e restaurantes, comércio etc.

Em fases de crise e de recessão, como as que estamos vivenciando não só nos países do Norte, mas também no Sul do mundo, a resultante é ainda mais conhecida: erosão devastadora dos empregos e corrosão e demolição exponencial dos direitos do trabalho (PRADELLA; MAROIS, 2015; ANTUNES, 2011).

Os exemplos são abundantes. As empresas inglesas ampliam a modalidade perversa de trabalho denominada zero hour contact, em que trabalhadores e trabalhadoras, especialmente no setor de serviços, ficam em disponibilidade integral para o capital, sem nenhuma contrapartida que garanta algum trabalho duradouro. E, por certo, desprovidos de quaisquer direitos, expandindo-se globalmente essa pragmática. Ressurgem, então, formas contemporâneas de trabalho aviltado, como nas Olimpíadas de 2016, no Rio de Janeiro, ou, anteriormente, nos trabalhos precarizados presentes na Copa do Mundo de 2014, ou ainda na Feira Internacional de Milão, na Itália, em 2015, realizada com muita precarização do trabalho que, por vezes, se aproximou do trabalho análogo à escravidão presente no mundo contemporâneo.

Novas palavras aparecem no dicionário do flagelo laborativo: voluntariado, empreendedorismo, pejotização, uberização, tudo isso em meio ao avanço real da devastação social. E, quando se consegue garantir algum emprego, a resultante é imediata: redução salarial, burla maior dos direitos sociais que aviltam o que resta da dignidade do trabalho, sem falar do enfraquecimento dos sindicatos e da redução das ações coletivas, que nos aproxima do que denominei como sociedade da terceirização total (ANTUNES, 2018).

Impulsionado pela lógica do capital financeiro, onde o tempo e o espaço se convulsionaram, o vilipêndio do trabalho é a contrapartida necessária na base da produção. Capital financeiro, com dinheiro gerando mais dinheiro na ponta fictícia do sistema, e um amálgama de formas precárias e pretéritas de trabalho nas cadeias globais produtivas de valor. Da China à Índia, dos EUA à Inglaterra, do México ao Brasil e Argentina, da Itália à Espanha, das Filipinas ao Haiti, difícil é fugir dessa realidade. Somente quando as resistências são fortes e amplas é que esse processo sofre limitações. Quando a resistência sindical é maior, a devastação é menor. Onde a resistência é mais fraca, os capitais globais avançam na demolição dos direitos do trabalho.

Vale o seguinte paralelo: se durante a vigência da empresa taylorista e fordismo, a força das empresas era mensurada pelo número de trabalhadores e trabalhadoras que 
nela atuavam, na era atual, das empresas flexíveis e digitalizadas do mundo financeirizado, quanto menos trabalho vivo existir nas empresas, mais produtiva elas são, mais global serão as suas possibilidades, mais transnacionais serão os seus perfis.

Logo, a pergunta é: qual será, então, o futuro do trabalho, na era do trabalho digital?

\section{A EXPLOSÃO DOS INTERMITENTES GLOBAIS}

Ao mesmo tempo que se amplia o contingente global de trabalhadores e trabalhadoras em luta de empregos, há uma redução monumental dos empregos, sendo que os que se mantêm empregados presenciam a corrosão completa dos seus direitos sociais. E, quando encontram algum labor, o fazem nos trabalhos ocasionais, intermitentes, seja nas plataformas digitais e aplicativos, call center, telemarketing, hotelaria, hipermercados, fast food, grande comércio, fábricas flexíveis e empresas em geral. Longe do que o ideário dominante pomposamente denomina como "nova classe média", o que se expande explosivamente pelo mundo são os precários, os intermitentes globais, os supérfluos que corroboram as teses da precarização estrutural do trabalho (ANTUNES, 2018, 2014; VAN DER LINDEN, 2013). Mas que, exatamente por conta disso, também se rebelam.

Alguns exemplos são emblemáticos. Em Portugal, em março de 2011, explodiu o descontentamento da "geração à rasca". Milhares de manifestantes, jovens e imigrantes, precarizados e precarizadas, desempregados e desempregadas, qualificados ou não, estamparam suas revoltas através de movimentos como o dos Precári@s inflexíveis. Simultaneamente, na Espanha, deflagrou-se o movimento dos indignados, jovens lutando contra as altas taxas de desemprego que lhes tolhem qualquer perspectiva de vida digna. Estudando ou não, são candidatos preferenciais ao desemprego ou, na melhor das hipóteses, ao trabalho precário.

$\mathrm{Na}$ Inglaterra, ocorreu um forte levante social que se iniciou depois que um trabalhador taxista negro foi assassinado pela polícia. Jovens pobres, negros, imigrantes, desempregados e desempregadas, se revoltaram e foram responsáveis pela primeira grande explosão social na Inglaterra depois do Poll Tax, revolta que sepultou o governo Thatcher.

Nos EUA, floresceu o movimento de massas Occupy Wall Street, denunciando a hegemonia dos interesses do capital financeiro, com suas nefastas consequências sociais: o aumento do desemprego e do trabalho precarizado que atingiu ainda mais duramente as condições de vida das mulheres, dos negros e dos imigrantes. 
Na Itália, com a eclosão conhecida como MayDay, em Milão, em 2001, floresceu a revolta do precariado, lutando por direitos e por uma representação autônoma dos jovens, imigrantes, qualificados ou não qualificados, desprovidos de direitos ${ }^{2}$.

Em Nápoles, desencadeou-se também um movimento similar ao do precariado, o Clash City Workers, uma simbiose entre o antigo proletariado agora ainda mais precarizado. Daí a denominação precariado, que se torna cada vez mais visível e global $^{3}$.

Essa corrosão dos direitos do trabalho tem gerado também novas formas de representação sindical para este novo contingente mais precarizado do proletariado, o autodenominado precariado. Além de seus próprios movimentos de perfil mais autônomos, presenciamos a criação da Confederazione Unitaria di Base (CUB), anos atrás e, mais recentemente, da Nuove Identitá di Lavoro (NIdiL) vinculada à CGIL (Confederazione Generale Italiana del Lavoro).

\section{AS CAUSAS DA PRECARIZAÇÃO GLOBAL}

Onde esses movimentos encontram suas raízes? Em um novo cenário perverso, no qual o zero hour contract (contrato de zero hora) é emblemático. Trata-se de uma modalidade de trabalho que viceja no Reino Unido e em outros países onde os contratos não têm determinação de horas. Trabalhadores e trabalhadoras (sempre também no feminino, dada a divisão sociosexual que conforma o mundo do trabalho) das mais diversas atividades ficam à disposição esperando uma chamada. E quando a recebem, ganham estritamente pelo que fizerem e nada recebem pelo tempo que ficaram à espera. $E$ os capitais informáticos da era financeira, numa engenhosa forma de escravidão digital, cada vez mais se utilizam dessa pragmática de flexibilização total do mercado de trabalho (ANTUNES, 2018; HUWS, 2003, 2014).

No Reino Unido, segundo os sindicatos, eles já totalizam mais de um milhão de trabalhadores e trabalhadoras, especialmente no setor de serviços.

O Uber é outro exemplo mais do que emblemático: trabalhadores e trabalhadoras com seus instrumentos de trabalho (autos) arcam com suas despesas de seguro, manutenção, alimentação etc. Enquanto isso, o "aplicativo", em verdade, uma

2 Ver San Precario. Disponível em: http://www.precaria.org/. Acesso em: 20 fev. 2020.

3 "Clash City Workers é um coletivo de trabalhadores e trabalhadoras, desocupados e desocupadas, denominados 'jovens precários'. A tradução de nosso nome significa algo como 'trabalhadores da metrópole em luta'. Nascido na metade de 2009, somos ativos particularmente em Nápoles, Roma, Florença, Pádua, Milão e Bergamo [...]”. (Ver ANTUNES, 2018). Disponível em: http://clashcityworkers.org/chi-siamo.html. Acesso em: 20 fev. 2020. 
corporação global, praticante do trabalho ocasional e intermitente, se apropria do sobretrabalho gerado pelos serviços dos motoristas, sem preocupação em relação aos deveres trabalhistas. A diferença principal em relação ao "contrato de zero hora" é que o uber não pode recusar trabalho. Se assim o fizer, depois de algumas chamadas, estará definitivamente descartado. O quadro é tão lépido que, ao mesmo tempo que essa empresa global amplia celeremente seus lucros, ela desenvolve um novo protótipo de veículo sem motorista, inteiramente automatizado e digitalizado que, aliás, foi responsável recentemente por uma morte por atropelamento nos EUA, quando "testava" seu "invento" sem trabalho humano direto. A Amazon combina venda virtual com trabalho profundamente manual (a embalagem de livros), ao mesmo tempo que já funciona com magazines sem trabalhadores vivos, sendo tudo controlado digitalmente.

É por isso que neste mundo do trabalho digital e flexível, o dicionário empresarial não para de "inovar". Veja-se o nosso exemplo tropical: "pejotização" nas mais distintas atividades como médicos, advogados, professores, bancários, eletricistas, trabalho do care (cuidadoras). Há também os "empreendedores", um exemplo de proprietários e proletários de si mesmos. Todos e todas com "metas" impostas que geram assédios, adoecimentos, depressões e suicídios. Os assédios que vêm ocorrendo na empresa Uber assumiram, recentemente, tal dimensão que levou inclusive à demissão de seu CEO.

No Brasil, recentemente, a imprensa noticiou que a Prefeitura de Ribeirão Preto pretendia contratar professores como avulsos, sem direitos, uma espécie de "Uber da educação", ou, como foi denominado pelos docentes de lá, "Professor Delivery". Não é demais lembrar que uma das máximas da (contra)reforma trabalhista do governo terceirizado de Temer e sua tropa parlamentar, sob imposição da CNI, FEBRABAN e dos grandes capitais, é a legalização do trabalho intermitente, que se soma à terceirização total, aprovada anteriormente. Explode, assim, a onda de contratação de trabalhadores e trabalhadoras intermitentes em grandes corporações que atuam no Brasil.

As empresas de fast food comemoraram efusivamente a implantação do trabalho intermitente e já há empresas de consultoria jurídica que se apresentam assim: "como demitir seus funcionários e contratá-los mais barato?”. E o Brasil já dá sinais de uma indigência que se aproxima perigosamente da Índia. Basta olhar as principais capitais do país, com seus bolsões de homens e mulheres, jovens, negros, etc., que compõem um enorme contingente que se encontra fora de qualquer padrão mínimo de humanidade. 


\section{Ricardo Antunes}

Outro exemplo recente dessas formas disfarçadas de exploração do trabalho são encontradas na Itália, onde se desenvolveu outra modalidade de trabalho ocasional, o trabalho pago a voucher. Os assalariados ganham um voucher pelas horas de trabalho efetivadas, segundo o salário mínimo (hora) praticado. Se já não bastasse esse vilipêndio, o empresariado oferece trabalhos excedentes por fora do voucher, com pagamento menor do que o mínimo. Não foi por outro motivo que essa modalidade de trabalho foi repudiada pelo sindicalismo de perfil mais crítico, o que levou a sua suspensão pelo governo, em 2017.

Assim, movida por essa lógica destrutiva, expande-se, em escala global, o que podemos denominar como uberização do trabalho. Como o trabalho online fez desmoronar a separação entre o tempo de vida no trabalho e fora dele, podemos presenciar o crescimento exponencial de uma era de escravidão digital. Na empresa "moderna", liofilizada, o trabalho que os capitais financeiros exigem é aquele flexível: sem jornadas preestabelecidas, sem remuneração fixa, sem atividade prédeterminada, sem direitos, nem sequer o direito de organização sindical. E até o sistema de "metas" é flexível: ela sempre deverá superar aquelas obtidas anteriormente (ANTUNES, 2018).

Com os serviços cada vez mais "comoditizados", com as tecnologias de informação e comunicação em galope estonteante, a divisão setorial existente entre agricultura, indústria e serviços está cada vez mais interseccionada (agroindústria, serviços industriais e indústria de serviços), cada vez mais submersa à lógica da mercadoria e do valor, pouco importando se este é resultante de trabalhos predominantemente materiais ou imateriais.

Contra a "rigidez" vigente nas fábricas do século do automóvel, a era do celular digital gera, então, sua tríade destrutiva em relação ao trabalho. Terceirização, informalidade e flexibilidade tornaram-se partes inseparáveis do léxico de empresa corporativa, seu novo leitmotiv. Expande-se o trabalho intermitente: hoje há trabalho por algumas horas e amanhã ele se evapora. As grandes corporações se enriquecem e o trabalho se depaupera. "Voluntariado" torna-se consolo imposto de modo quase compulsório e "empreendedorismo" é o novo elixir de uma vida desprovida de sentido, visível quando o mito se desvanece.

$\mathrm{Na}$ contraface real, os enormes contingentes de imigrantes globais, em seus novos fluxos migratórios, ampliam ainda mais os bolsões de trabalhadores sobrantes, descartáveis, subempregados e desempregados em amplitude planetária. (BASSO; PEROCCO, 2008; RONCATO, 2013). 
É importante assinalar que o trabalho online e digital que produz Iphone, Ipad e similares não pode existir, entretanto, sem o trabalho que extrai o mineral. O trabalho digital, então, não se efetiva sem o pior dos trabalhos manuais (HUWS, 2003, 2015) É esse, então, o novo "espírito do tempo": de um lado, a disponibilidade perpétua para o labor, facilitada pela expansão do trabalho online. De outro, propaga-se a flexibilidade total. Florescem, então, os novos escravos intermitentes globais.

A busca de um novo modo de vida tornou-se, portanto, um imperativo societal de nosso tempo. E a atividade vital, como Marx caracterizou o trabalho, está, uma vez mais, no centro deste empreendimento humano que se torna cada vez mais inevitável.

\section{QUAL TRABALHO TEM FUTURO?}

Como o sistema global do capital macula tanto as esferas da vida dentro e fora do trabalho, a desfetichização da sociedade do consumo tem como corolário imprescindível a demolição no modo de produção das coisas, tal como ela é estruturada pelo capital. O que torna a sua conquista muito mais difícil, se não se inter-relaciona decisivamente a ação pelo tempo livre com a luta contra a lógica do capital e a vigência do trabalho abstrato.

Uma vida cheia de sentido em todas as esferas do ser social, dada pela omnilateralidade humana, somente poderá se efetivar através da demolição das barreiras existentes entre tempo de trabalho e tempo de não-trabalho, de modo que, a partir de uma atividade vital cheia de sentido, autodeterminada, para além da divisão hierárquica que subordina o trabalho ao capital hoje vigente e, portanto, sob bases inteiramente novas, possa se desenvolver uma nova sociabilidade. E se o trabalho tornar-se novamente dotado de sentido será também (e decisivamente) através do verdadeiro tempo livre, do ócio, em sua forma mais autêntica e livre, que o ser social poderá humanizar-se e emancipar-se em seu sentido mais profundo (ANTUNES, 2013).

Posso dar aqui um exemplo aparentemente simples, pois, se o fundamento da ação coletiva for voltado radicalmente contra as formas de alienação e estranhamento no mundo das mercadorias, a luta imediata pela redução da jornada ou do tempo de trabalho torna-se inteiramente compativel com o direito ao trabalho (em jornada

$4 \mathrm{Na}$ recente Mostra Contemporânea Internacional da Ecofalante, espetaculares fotografias do trabalho precário global foram apresentadas: Behemoth, de Zhao Liang (China/ França, 2015), Machines, de Rahul Jain (Índia/ Alemanha/ Finlândia, 2016); Consumed, de Richard Seymour (Reino Unido, 2015); Brumaire, de Joseph Gordillo (França, 2015); What We Have Made, de Fanny Tondre (França, 2016) e Factory Complex, de Heung-Soon Im. (Coreia do Sul, 2015).

Laborare. Ano III, Número 4, Jan-Jun/2020, pp. 6-14. ISSN 2595-847X. https://trabalhodigno.org/laborare DOI: https://doi.org/10.33637/2595-847x.2020-46 
reduzida e sem redução de salário). Ao invés de serem excludentes, tornam-se necessariamente complementares.

E a construção societal dotada de um trabalho cheio de sentido e por uma vida autêntica fora do trabalho, por um tempo disponível para o trabalho e por um tempo verdadeiramente livre fora do trabalho - ambos, portanto, fora do controle e comando do sistema de metabolismo social do capital (MÉSZÁROS, 2002) - torna-se vital para a construção de uma sociedade não mais regulada pelo sistema do capital e seus mecanismos de subordinação, sujeição e outros tantos constrangimentos humano-sociais.

Eliminado o dispêndio de tempo excedente para a produção de mercadorias (o tempo da geração de mais-valia) e também todo o tempo de produção destrutivo e supérfluo (esferas estas controladas pelo capital), será possível resgatar o verdadeiro sentido estruturante do trabalho vivo, da "atividade vital" contra o sentido (des)estruturante do trabalho abstrato para o capital.

Isso porque, sob o sistema de metabolismo social do capital, o trabalho que estrutura o capital desestrutura o ser social. O trabalho assalariado, que dá sentido ao capital, gerara uma subjetividade inautêntica no próprio ato de trabalho. Numa forma de sociabilidade superior, em um novo modo de vida, o trabalho, ao reestruturar o ser social, terá como imperativo central desestruturar, e de forma cabal, o sistema de metabolismo social do capital. E esse mesmo trabalho autodeterminado, ao mesmo tempo que torna sem sentido o capital (eliminando-o), gerará as condições humanosociais necessárias para o florescimento de uma subjetividade autêntica e emancipada, dando um novo sentido ao trabalho e para a humanidade.

\section{REFERÊNCIAS}

ANTUNES, Ricardo. Adeus ao Trabalho? 16. ed. especial de 20 anos da publicação, revista e ampliada. São Paulo: Cortez, 2014.

ANTUNES, Ricardo. O Continente do Labor. São Paulo: Boitempo, 2011.

ANTUNES, Ricardo. O Privilégio da Servidão. São Paulo: Boitempo, 2018.

ANTUNES, Ricardo. Os Sentidos do Trabalho. São Paulo: Boitempo, 2013.

BASSO, P.; PEROCCO, F. Gli immigrati in Europa. Disuguaglianze, razzismo, lotte. 3. ed. Milano: Angeli, 2008. 
CLASS CITY WORKERS. Dove $i$ Nostri: Lavoro, classe e movimenti nell'Itália della crisi. Luca: La Casa USHER, 2014.

CHESNAIS, François. A Mundialização do Capital. São Paulo: Ed. Xamã, 1996.

HUWS, Ursula. Labor in the Global Digital Economy: The Cybertariat Comes of Age, Nova Iorque/Londres: Monthly Review Press/The Merlin Press, 2014.

HUWS, Ursula. The Making of a Cybertariat (virtual work in a real world). Nova Iorque/Londres: Monthly Review Press/The Merlin Press, 2003.

MÉSZÁROS, István. Para Além do Capital. São Paulo: Ed. Boitempo, 2002.

PRADELLA, Lucia; MAROIS, Thomas (Ed.). Polarising development: alternatives to neoliberalism and the crisis. London: Pluto Press, 2015.

PREVITALI, Fabiane et al. (org.). Desafios do Trabalho e da Educação no Século XXI. Vol. II, Previtali. Uberlândia/Minas Gerais: Navegando Publicações, 2019.

RONCATO, Mariana Shinohara. Dekassegui, cyber-refugiado e working poor: o trabalho imigrante e o lugar do outro na sociedade de classe. 2013. 248 p. Dissertação (Mestrado em Sociologia). Instituto de Filosofia e Ciências Humanas, Universidade Estadual de Campinas, Campinas, 2013.

VAN DER LINDEN, Marcel. Trabalhadores do Mundo (Ensaios para uma história global do trabalho). Campinas/Ed. Unicamp, 2013.

Recebido: 30/03/2020

Revisado: 11/05/2020

Aprovado: 08/06/2020 